\title{
Management of postoperative fecal incontinence by pediatric surgeons in Nigeria: a pilot study
}

Taiwo A. Lawal(D)

\begin{abstract}
Background: Fecal incontinence is a challenging problem in pediatric surgical practice as it occurs in 25 to $50 \%$ of patients who have undergone surgery for anorectal malformation and in 5 to $23 \%$ after transanal pull-through for Hirschsprung disease. Fecal incontinence impacts on the quality of life of patients; hence, it is important that optimum management is instituted. The management of fecal incontinence in children in sub-Saharan Africa is largely unreported. The study, therefore, evaluated the management practices regarding fecal incontinence by pediatric surgeons in Nigeria.
\end{abstract}

Results: A total of 37 pediatric surgeons participated in the cross-sectional pilot study. The mean length of practice as specialists was 9.7 ( \pm 7.8 ) years. The majority, 33 (89.2\%), were males; $23(62.2 \%)$ were $\leq 45$ years of age, and 14 (37.8\%) had practiced as consultant pediatric surgeons for $\geq 10$ years.

When presented with a patient with anorectal malformation and recto-bladder neck fistula or Hirschsprung disease who developed fecal incontinence after surgery, 25 (67.6\%) and 22 (59.5\%), respectively, will combine modalities in managing the patient. Bowel management $(81.1 \%$ and $83.8 \%$ respectively) was the most commonly selected option of managing postoperative fecal incontinence. Other options selected for the management of postoperative fecal incontinence were as follows: examination under anesthesia (43.2\% and 37.8\%), constipating diet (43.2\% and $35.1 \%)$, re-operation (24.3\% and $27.0 \%)$, and diverting colostomy (21.6\% and $16.2 \%)$ for anorectal malformation and Hirschsprung disease respectively. There were no statistically significant associations between the length of practice as specialist pediatric surgeons and the selection of single vs. multiple treatment options for a patient with fecal incontinence after surgery either for anorectal malformation or Hirschsprung disease.

Conclusions: A combination of modalities will be adopted by at least $60 \%$ of pediatric surgeons in Nigeria to manage postoperative pediatric fecal incontinence with bowel management favored by over $80 \%$ of specialists surveyed.

Keywords: Anorectal malformation, Bowel management, Enema, Fecal incontinence, Hirschsprung disease

\section{Background}

Pediatric fecal incontinence implies soiling of the underwear of a child who ought to have attained the age of toilet training. Fecal incontinence is a challenging problem in pediatric surgical practice as it may complicate

Correspondence: taiwo.lawal@hotmail.com

Division of Pediatric Surgery, Department of Surgery, College of Medicine, University of Ibadan and University College Hospital, PMB 5017, Ibadan 200212, Nigeria surgery for the two most common colorectal conditions treated in the specialty, i.e., anorectal malformation and Hirschsprung disease [1]. Fecal incontinence occurs in 25 to $50 \%$ of children who have undergone surgery for anorectal malformation [2-4]. Fecal incontinence is commoner in patients with anorectal malformation that is associated with poorer prognosis [5-8]. Children with anorectal malformation and recto-bladder neck fistula

\section{Springer Open}

(c) The Author(s). 2020 Open Access This article is licensed under a Creative Commons Attribution 4.0 International License, which permits use, sharing, adaptation, distribution and reproduction in any medium or format, as long as you give appropriate credit to the original author(s) and the source, provide a link to the Creative Commons licence, and indicate if changes were made. The images or other third party material in this article are included in the article's Creative Commons licence, unless indicated otherwise in a credit line to the material. If material is not included in the article's Creative Commons licence and your intended use is not permitted by statutory regulation or exceeds the permitted use, you will need to obtain permission directly from the copyright holder. To view a copy of this licence, visit http://creativecommons.org/licenses/by/4.0/. 
are incontinent of feces in 80 to $100 \%$ of cases postoperatively $[9,10]$.

Transanal pull-through surgery for Hirschsprung disease is complicated by fecal incontinence in 5 to $23 \%$ of patients $[7,11,12]$. In this particular instance, fecal incontinence may occur following injury to the anal canal during the pull-through operation, especially with limited experience and failure to adequately recognize and protect the dentate line [5].

Fecal incontinence is a much larger problem than reported [9], and it is associated with impairment of several domains of quality of life measures [3, 13]. The impact on the quality of life is similar in patients treated either for anorectal malformation or Hirschsprung disease [3]. It is, thus, important to manage pediatric fecal incontinence appropriately and adequately to improve the quality of life of patients.

The management of fecal incontinence in children in sub-Saharan Africa is largely unreported. This study, therefore, evaluated the management practices regarding fecal incontinence by pediatric surgeons in Nigeria.

\section{Methods}

A cross-sectional study was conducted through the use of a self-administered questionnaire given to pediatric surgeons at the annual national conference of the association that took place in September 2018 in Kano, Nigeria. The current study was part of a larger survey of all consenting pediatric surgeons at the conference [5]. The questionnaire contained a section on management of fecal incontinence using two case scenarios. The responses to the questions in this section constituted the tool used for the current study. The first case was a patient who had posterior sagittal anorectoplasty (PSARP) on account of anorectal malformation with rectobladder neck fistula and developed fecal incontinence after surgery. The second case had Hirschsprung disease and developed fecal incontinence after a pull-through operation. The respondents were asked what they would do in each instance.

They were given the following options: commencement of bowel management, construct a diverting colostomy, repeat the PSARP, examine the patient under anesthesia, place the patient on constipating diet, and the choice of giving another modality to be used in the first case. In the second case, they were presented with the following possibilities: commence bowel management, construct a diverting colostomy or ileostomy, repeat the pull-through procedure, examine the patient under anesthesia, repeat a rectal biopsy, place the patient on constipating diet, and the choice of other options. They were allowed to select single or multiple options. Only respondents who consented to participate in the study and responded to the case scenarios were recruited for the current study.

The anonymized responses were collated, using SPSS version 23 , and data summarized using descriptive statistics: means (and standard deviations), proportions, and percentages. Chi-square statistics was used to evaluate association between the length of practice as a pediatric surgeon and selection of single vs. multiple modalities of treatment for each case scenario presented. Ethical approval for the study was granted by the joint University of Ibadan and University College Hospital Ethics Review Committee.

\section{Results}

A total of 37 pediatric surgeons who had practiced as specialists for $9.7( \pm 7.8)$ years participated in the pilot study. The majority, 33 (89.2\%), were males; 23 (62.2\%) were 45 years of age or younger, and $14(37.8 \%)$ had practiced as consultant pediatric surgeons for 10 years or longer.

When presented with a patient with anorectal malformation and recto-bladder neck fistula who developed fecal incontinence after PSARP, 25 (67.6\%) will combine modalities in managing the patient while $12(32.4 \%)$ will utilize only one form of treatment. The selected options of treatment for the case are outlined in Table 1.

In the second case scenario, $22(59.5 \%)$ will combine treatments and 15 (40.5\%) will adopt a single option of treatment. Bowel management $(83.8 \%)$ was the most commonly selected option of managing fecal incontinence occurring after pull-through for Hirschsprung disease (Table 2).

There were no statistically significant associations between the length of practice as specialist pediatric surgeons and the selection of single vs. multiple treatment options for a patient with fecal incontinence after surgery either for anorectal malformation or Hirschsprung disease (Table 3).

Table 1 Modalities selected by the respondents for the management of fecal incontinence after PSARP for anorectal malformation

\begin{tabular}{lll}
\hline Treatment option & Frequency* $^{*}$ & Percentage \\
\hline Bowel management & 30 & 81.1 \\
Diverting colostomy & 8 & 21.6 \\
Repeat PSARP & 9 & 24.3 \\
EUA & 16 & 43.2 \\
Constipating diet & 16 & 43.2 \\
Others & 1 & $2.7 \%$
\end{tabular}

PSARP posterior sagittal anorectoplasty, EUA examination under anesthesia *Multiple responses allowed 
Table 2 Treatment options favored by the respondents for the management of the patient with fecal incontinence after pullthrough for Hirschsprung disease

\begin{tabular}{lll}
\hline Treatment option & Frequency $^{\text {a }}$ & Percentage \\
\hline Bowel management & 31 & 83.8 \\
Diverting colostomy/ileostomy & 6 & 16.2 \\
Repeat the pull-through & 10 & 27.0 \\
EUA & 14 & 37.8 \\
Repeat biopsy & 11 & 29.7 \\
Constipating diet & 13 & 35.1 \\
Others & 0 & 0 \\
\hline
\end{tabular}

EUA examination under anesthesia

${ }^{a}$ Multiple responses allowed

\section{Discussion}

This was a survey of management practices of pediatric surgeons on fecal incontinence in a country in subSaharan Africa. The design was cross-sectional and utilized case scenarios making it as practical as possible to simulate actual patient encounters. Hence, the responses could be approximated to what would likely happen to patient management under the care of the specialists. Another strength of the study was that $62 \%$ of the respondents were 45 years of age or younger; hence, this cohort is likely to be active in pediatric surgical practice for much longer. A major limitation was that the survey was deployed at a conference; hence, those who did not attend the conference were excluded, as a result of the methodology employed. A more comprehensive survey of all practicing pediatric surgeons in the country would have been more representative of the management practices regarding fecal incontinence. Nonetheless, this was the first of such survey in the region, and it provides a snapshot of the management of postoperative pediatric fecal incontinence. Another limitation was that the options given in the questionnaire could have limited the choices of the surgeons. However, there was an option

Table 3 Association between length of practice as pediatric surgeons and multimodal management of fecal incontinence

\begin{tabular}{|c|c|c|c|c|}
\hline \multirow{2}{*}{$\begin{array}{l}\text { Modality of } \\
\text { treatment }\end{array}$} & \multicolumn{2}{|l|}{ Length of practice } & \multirow[t]{2}{*}{$x^{2}$} & \multirow{2}{*}{$\begin{array}{l}\boldsymbol{p} \\
\text { value }\end{array}$} \\
\hline & $<10$ years, $\boldsymbol{n}(\%)$ & $\geq 10$ years, $\boldsymbol{n}(\%)$ & & \\
\hline \multicolumn{5}{|c|}{$\begin{array}{l}\text { Fecal incontinence in ARM with recto-bladder neck fistula after } \\
\text { PSARP }\end{array}$} \\
\hline Single modality & $6(50.0)$ & $6(50.0)$ & 1.117 & 0.291 \\
\hline Multiple modalities & $17(68.0)$ & $8(32.0)$ & & \\
\hline \multicolumn{5}{|c|}{ Fecal incontinence in HD after pull-through procedure } \\
\hline Single modality & $8(53.3)$ & $7(46.7)$ & 0.836 & 0.361 \\
\hline Multiple modalities & $15(68.2)$ & $7(31.8)$ & & \\
\hline Total & $23(62.2)$ & $14(37.8)$ & & \\
\hline
\end{tabular}

ARM anorectal malformation, HD Hirschsprung disease, PSARP posterior sagittal anorectoplasty of "other option," which could have taken care of differences of opinion. Furthermore, in actual surgical practice, one may decide on different options based on circumstances at play. It is not unexpected that some of the options are preliminary to other choices.

Multiple modalities would be employed by $68 \%$ and $60 \%$ of the pediatric surgeons in the study for the management of patients with anorectal malformation and Hirschsprung disease, respectively, who develop postoperative fecal incontinence. Furthermore, there were no statistically significant differences based on the experience of pediatric surgeons in the adoption of multimodal treatment. The use of combination of treatment to solve the challenges of fecal incontinence is widely supported in the literature $[2,6,9,14-16]$. A major recommendation in successfully treating patients with fecal incontinence is the need to differentiate between pseudo incontinence and true incontinence [6-8, 15]. Furthermore, the specialist should have an understanding of the colonic characteristic, largely obtained from clinical history and contrast enema, in each patient. Patients who are hypomotile, being prone to dilated, slow moving colon, are treated differently from those with hypermotile colon that is more likely to result in rapid transit of watery stools. Whereas hypomotile patients require large volumes of water for enema, hypermotile patients require smaller volume and less concentrated enemas. The use of different modalities in combination results in a significantly better response to the management of fecal incontinence $[2,9,15]$.

Bowel management would be used by $81 \%$ and $84 \%$ of the respondents to manage fecal incontinence in patients with anorectal malformation and Hirschsprung disease respectively. This is encouraging as it shows a great deal of awareness of the role of bowel management in the treatment of pediatric fecal incontinence. Bowel management program is a set of processes or activities designed to keep a patient with fecal incontinence artificially clean without soiling the underwear in between enemas. The program consists of administration of enemas-retrograde or anterograde, dietary modification, and use of medications (to slow down the colon, e.g., loperamide, Smecta; or to provide bulk, e.g., pectin; or to stimulate motility, e.g., laxatives) $[2,14,15,17-19]$. Bowel management, when utilized appropriately and adequately, individualized according to the patient's age, type of incontinence, severity, and response to the treatment regimen [15], has been shown to be successful in $95 \%$ of pediatric patients with true fecal incontinence $[2,15]$.

Constipating diet was selected by $43.2 \%$ and $35.1 \%$ of the pediatric surgeons as methods of management of fecal incontinence occurring after surgery for anorectal malformation and Hirschsprung disease respectively. Constipating diet works on the basis of slowing down 
transit time within the colon. The use of constipating diet is likely to be successful in patients who had been clean on an enema regime. Constipating diet is most useful in patients with hypermotile colon with frequent loose stools $[2,16]$. Patients who have had large colonic resections may also benefit from constipating diet.

A diverting colostomy will be used by $21.6 \%$ of the respondents to manage fecal incontinence after surgery for a patient with anorectal malformation and recto-bladder neck fistula. This requires further interrogation because a colostomy is not a first-line option in the management of patients with postoperative fecal incontinence. There are indeed a few indications for diverting colostomy in such patients: if the examination under anesthesia (EUA) and other investigations show an inadequate anoplasty that will be amenable to reoperation or if there is severe prolapse and the expertise for a single stage reoperation is not available. It is indeed noteworthy that $43.2 \%$ and $37.8 \%$ of the pediatric surgeons will perform an EUA in managing the patient with fecal incontinence postoperation for anorectal malformation and Hirschsprung disease respectively. The EUA will afford an opportunity to examine the size and location of the anoplasty within or outside the sphincter mechanism [6, 7]. The anal canal will be inspected during EUA in the patient who has had a pull-through operation to ascertain the intactness of the dentate line, which is a requirement for adequate proprioception and establishment of bowel control $[5,7]$. A permanent colostomy is not supported, in the management of patients with anorectal malformation who developed fecal incontinence in order to ensure a good quality of life for affected patients [20].

\section{Conclusion}

A combination of modalities will be adopted by at least $60 \%$ of pediatric surgeons in Nigeria to manage postoperative pediatric fecal incontinence with bowel management favored by over $80 \%$ of specialists surveyed.

\section{Abbreviations}

ARM: Anorectal malformation; EUA: Examination under anesthesia;

HD: Hirschsprung disease; PSARP: Posterior sagittal anorectoplasty

\section{Acknowledgements}

All the pediatric surgeons who responded to the survey are acknowledged.

\section{Author's contributions}

TAL was the sole author of the work. The author read and approved the final manuscript.

\section{Author's information}

TAL is a pediatric surgeon, with major emphasis on pediatric colorectal care, practicing in a university teaching hospital in Nigeria. He received postfellowship pediatric colorectal training at the Colorectal Center for Children, Cincinnati Children's Hospital Medical Center, Cincinnati, USA, and the Center for Colorectal and Pelvic Reconstruction, Nationwide Children's Hospital, Columbus, USA, under the tutelage of Dr. Alberto Peña and Dr. Marc Levitt.

\section{Funding}

No external funding was received for the conduct of this study.

Availability of data and materials

The datasets used and/or analyzed during the current study are available from the corresponding author on reasonable request.

\section{Ethics approval and consent to participate}

Ethical approval was obtained from the joint University of Ibadan and University College Hospital Ethics Review Committee (UI/EC/18/0432). Verbal consent to participate was obtained from each respondent for the study. A verbal consent was obtained in each instance since this was a survey, which involved no personal data collection.

\section{Consent for publication}

Consent was obtained from each respondent to participate in the study.

\section{Competing interests}

The author declares that he has no competing interests.

Received: 1 June 2020 Accepted: 13 July 2020

Published online: 10 September 2020

\section{References}

1. Lawal TA, Olulana DI, Ogundoyin OO. Spectrum of colorectal surgery operations performed in a single paediatric surgery unit in sub-Saharan Africa. Afr J Paediatr Surg. 2014;11(2):128.

2. Bischoff A, Levitt MA, Pena A. Bowel management for the treatment of pediatric fecal incontinence. Pediatr Surg Int. 2009;25(12):1027-42.

3. Mathias AL, Tannuri ACA, Ferreira MAE, Santos MM, Tannuri U. Validation of questionnaires to assess quality of life related to fecal incontinence in children with anorectal malformations and Hirschsprung's disease. Rev Paul Pediatr. 2016;34(1):99-105.

4. Oyania F, Ogwal A, Nimanya S, Muzira A, Kakembo N, Kisa P, et al. Long term bowel function after repair of anorectal malformations in Uganda. J Pediatr Surg. 2019 Dec 11;S0022-3468(19)30873-5. doi: https://doi.org/10. 1016/j.jpedsurg.2019.11.015. Online ahead of print.

5. Lawal TA. Influence of workshop attendance on management of pediatric fecal incontinence in Nigeria. Ann Pediatr Surg. 2019;15(1):5.

6. Levitt MA, Pena A. Pediatric fecal incontinence: a surgeon's perspective. Pediatr Rev. 2010;31(3):91.

7. Levitt MA, Peña A. Outcomes from the correction of anorectal malformations. Curr Opin Pediatr. 2005:17(3):394-401.

8. Peña A, Guardino K, Tovilla J, Levitt M, Rodriguez G, Torres R. Bowel management for fecal incontinence in patients with anorectal malformations. J Pediatr Surg. 1998;33(1):133-7.

9. Pfeifle VA, Holland-Cunz S. Bowel management in children: how to keep children clean. Ann Pediatr Surg. 2017;13(4):175-81.

10. Samuk I, Bischoff A, Hall J, Levitt M, Peña A. Anorectal malformation with rectobladder neck fistula: a distinct and challenging malformation. J Pediatr Surg. 2016;51(10):1592-6.

11. Khazdouz M, Sezavar M, Imani B, Akhavan H, Babapour A, Khademi G. Clinical outcome and bowel function after surgical treatment in Hirschsprung's disease. Afr J Paediatr Surg. 2015;12(2):143-7.

12. Menezes $M$, Corbally M, Puri P. Long-term results of bowel function after treatment for Hirschsprung's disease: a 29-year review. Pediatr Surg Int. 2006;22(12):987-90.

13. Tannuri ACA, Ferreira MAE, Mathias AL, Tannuri U. Long-term evaluation of fecal continence and quality of life in patients operated for anorectal malformations. Rev Assoc Médica Bras. 2016;62(6):544-52.

14. Bischoff A, Levitt MA, Peña A. Update on the management of anorectal malformations. Pediatr Surg Int. 2013:29(9):899-904.

15. Elfiky MM, Gad MA, Mohamed M, Kaddah SN, El Tagy GH. Implementation of a bowel management program in the treatment of incontinence in children for primary healthcare providers. Ann Pediatr Surg. 2017;13(1):21-5.

16. Wood RJ, Levitt MA. Anorectal malformations. Clin Colon Rectal Surg. 2018; 31(02):61-70.

17. Lawal TA, Rangel SJ, Bischoff A, Peña A, Levitt MA. Laparoscopic-assisted Malone appendicostomy in the management of fecal incontinence in children. J Laparoendosc Adv Surg Tech. 2011;21(5):455-9. 
18. Malone PS, Ransley PG, Kiely EM. Preliminary report: the antegrade continence enema. Lancet. 1990;336(8725):1217-8.

19. Rangel SJ, Lawal TA, Bischoff A, Chatoorgoon K, Louden E, Peña A, et al. The appendix as a conduit for antegrade continence enemas in patients with anorectal malformations: lessons learned from 163 cases treated over 18 years. J Pediatr Surg. 2011;46(6):1236-42.

20. Kiely EM, Ade-Ajayi N, Wheeler R. Antegrade continence enemas in the management of intractable faecal incontinence. J R Soc Med. 1995;88(2): 103P-4P.

\section{Publisher's Note}

Springer Nature remains neutral with regard to jurisdictional claims in published maps and institutional affiliations.

\section{Submit your manuscript to a SpringerOpen ${ }^{\circ}$ journal and benefit from:}

- Convenient online submission

- Rigorous peer review

- Open access: articles freely available online

- High visibility within the field

- Retaining the copyright to your article

Submit your next manuscript at $\boldsymbol{\sim}$ springeropen.com 